\title{
The Practice of Surgical Doctors toward Cutaneous Abscess Drainage in Khartoum and Bahri Localities Teaching Hospitals
}

\author{
Nizar Ismail ${ }^{1 \mathbf{a}}$, Saifaldawlla Musa ${ }^{2 \mathbf{a}}$, Kareemaldin Elsamani ${ }^{3 \mathbf{a}}$, Amro Mohamed ${ }^{\text {4a }}$, Abubakir Abd Elmonem Elhaj ${ }^{5 a}$, Mounkaila \\ Noma $^{6}$, Mogadam BE Mogadam ${ }^{7 *}$, Mohammed Hamad ${ }^{\mathbf{8}}$, Amin Ahmed', Muneeb Adam ${ }^{\mathbf{1 0}}$, Seddig Ali ${ }^{\mathbf{1 1}}$, Alamin Mohamed ${ }^{\mathbf{1 2}}$, \\ Mohammed Ismail ${ }^{13}$ \\ ${ }^{1}$ Trauma and Orthopedics Department, Buckinghamshire NHS Trust, Buckinghamshire, UK. \\ ${ }^{2}$ University of Medical Sciences and Technology, Khartoum, Sudan. \\ ${ }^{3}$ General Surgery Department, Peterborough City Hospital, Peterborough, UK. \\ ${ }^{4}$ Elite Pharma, Khartoum, Sudan. \\ ${ }^{5}$ Pharmaceutical Department, International University of Africa, Khartoum, Sudan. \\ ${ }^{6}$ Research Methodology and Biostatistics department, University of Medical Sciences and Technology, Khartoum, Sudan. \\ ${ }^{7}$ Microbiology Department, University of Al-Butana, Gezira, Sudan. \\ 8 Medicine Department, Flushing Hospital Medical Center, New York, USA. \\ 9 Heart Failure clinic, Cardiology Department, Ahmed Gasim Hospital, Khartoum, Sudan. \\ ${ }^{10}$ Emergency Department, Association Specialized Hospital, Khartoum, Sudan. \\ ${ }^{11}$ Health Insurance, Sharg Darfur State, Sudan. \\ ${ }^{12}$ Emergency Department, Ribat University Hospital, Khartoum, Sudan. \\ ${ }^{13}$ Anatomy Department, Elrazi University, Khartoum, Sudan.
}

Abstract:

\section{$>$ Background:}

Cutaneous abscesses are infections of the skin and soft tissue, usually caused by the Staphylococcus aureus organisms. The study aimed to describe the patterns of doctor's practice toward cutaneous abscess management.

\section{$>$ Methods:}

A facility descriptive Cross-sectional base study conducted among the doctors of the surgery emergency departments of five teaching hospitals in Khartoum and Bahri localities that perform emergency operations for superficial cutaneous abscesses, Total coverage of the study population data collected through predesigned questionnaires that included different variables representing the medical history, physical examination, investigation and treatment of cutaneous abscess.

\section{$>$ Results:}

Out of 127 participants included in the study from 5 hospitals, with mean age of $\mathbf{2 6 . 6 6}$ years and mean of months surgical experience 19.2. Out of $24.4 \%$ of the participants were provided by the hospital protocol of management, $72.4 \%$ were found to be operating one septic list per duty and $76.4 \%$ of the participants following senior instructions in their practice. Only 46.5\% inquired prior antibiotic usage for the abscess in medical history, $31.5 \%$ checked for respiratory rate, $33.1 \%$ obtained blood culture, $\mathbf{7 4 . 0 \%}$ did not inject local anesthetics at the abscess roof, $96.1 \%$ followed incision and drainage, $\mathbf{2 2 . 0 \%}$ followed aspiration and antibiotics, $87.4 \%$ of the participants routinely prescribing post-operative antibiotics for every cutaneous abscess patients and most of them prescribing Augmentin. Only 51.2\% were following daily dressing manner for abscess patients.

\section{$>$ Conclusions:}

Study participants showed different patterns of practice in cutaneous abscess management, senior instructions determined the majority practice and routine prescription of postoperative antibiotics was one of the most important negative findings of the study. Important details of cutaneous abscess management were not covered in the guidelines including anesthesia, operative details and dressing patterns.

Keywords:- Cutaneous abscess, Khartoum, Bahri, Practice, management.

\section{INTRODUCTION}

Cutaneous abscesses are infections of the skin and soft tissue, presenting as painful, tender, and fluctuant red nodules, owing to the host immune response acting to isolate the infection from its surroundings. Cutaneous abscesses are typically polymicrobial, containing bacteria that constitute the normal skin flora $(\sim 25 \%$ of cutaneous abscesses caused by Staphylococcus aureus) and often combined with organisms from adjacent mucous membranes ${ }^{[1]}$. Local inflammatory signs of cutaneous abscesses; extreme tenderness to touch, localized swelling, erythema, temperature, the appearance of tight, shiny skin. Fluctuation is a reliable sign when present, although its absence does not rule out a deep abscess or an abscess in tissues with extensive fibrous components, such as the breast, the perianal area, and fingertips. If the diagnosis is equivocal, a large gauge needle can be used to prove the 
presence of pus within the cavity under aseptic conditions [2]. Ultrasonography usage for confirmation of doubtful cutaneous abscess is recommended especially when there are unclear history and examination, in addition the presence of lesion cellulitis ${ }^{[3]}$. Regarding to the preparation of patients, Investigation is not needed for patients with uncomplicated cutaneous abscess, however patient with symptoms and signs of Systemic Inflammatory Response Syndrome (SIRS) may needs complete blood cell (CBC) count, Creatinine level Blood culture and sensitivity, Creactive protein level, Bicarbonate level and Creatine phosphokinase level. Sometime must be need to Local, regional and general anesthesia are for cutaneous abscess drainage depending on abscess cavity ${ }^{[4]}$.

Incision with skin crease as far as possible is recommended for cutaneous abscess drainage to prevent unsightly scars, probing in order to break the loculi and drain the pus pockets is mandatory, then irrigation with normal saline is used to wash the content of the abscess cavity from blood, cells debris, and pus. Packing is controversy process, and dressing should be every 24 hours until the disappearance of pus and presence of healthy granulation tissue in the cavity ${ }^{[4]}$. Some operative details of abscess management and recommended abscess incision, coupled with a thorough evacuation of pus and probing of the cavity to break up loculation is the mainstay of therapy. Incision management however, continues to be a wider spectrum, with some physicians opting to cover the wound with the sterile dressing, whereas others choose to pack and close the wound, even suturing the wound at times ${ }^{[5]}$.

Direct Gram stain and culture of pus is recommended, but treatment without these modalities is reasonable in typical cases. The decision to administer antibiotics without culture results (usually directed against staphylococcus aureus), depends on the presence or absence of the features of SIRS, such as Temperature $>38^{\circ} \mathrm{C}$ or $<36^{\circ} \mathrm{C}$, tachypnea $>24$ breaths per minute, tachycardia $>90$ beats per minute, white blood cell count $>12000$ or $<4000$ cells $/ \mu \mathrm{L}$. A recurrent abscess is also an indication of antibiotics for 5 to 10 days after incision, drainage and obtaining of culture and sensitivity. An antibiotic active against Methicillin Resistance Staphylococcus aureus (MRSA) is recommended for patients with abscesses who have markedly impaired host defenses or in patients with SIRS and hypotension ${ }^{[1]}$.

The contrary to popular belief the addition of systemic antibiotics to incision and drainage of cutaneous abscesses does not improve cure rates even in abscesses due to MRSA, noting that the effect of systemic antibiotics was oriented towards reducing recurrence rates and was moderate. However, patients with immune compromise, impaired host defenses and signs of systemic infection should be given systemic antibiotics. Additional indications for the use of systemic antibiotics include multiple abscesses extremes of age, lack of response to incision and drainage ${ }^{[5]}$. Jon Hopkins antibiotics guidelines added the association of septic phlebitis and difficult sites of complete drainages such as face and genitalia as an additional indication for antibiotic prescription ${ }^{[6]}$.

Antibiotics that recommended by the Guidelines for the Diagnosis and Management of Skin and Soft Tissue Infections are Dicloxacillin, Cephalexin, Erythromycin and Amoxicillin-clavulanate, which represent different choices of antibiotics for the cutanous abcess ${ }^{[5]}$. Johns Hopkins guidelines of antibiotics recommending oral trimethoprimsulfamethoxazole (co-trimoxazole) or doxycycline or clindamycin as choices for cutaneous abscess management. Parenteral vancomycin is recommended for severe cases ${ }^{[6]}$. Usage of antibiotics for abscess management without draining will lead to a formation of Antibioma which is a large sterile swelling, has a brownish color and needs several weeks to resolve ${ }^{[7]}$. Another study on evaluate the use of systemic antibiotics, the improvement of cure rates in patients with simple abscesses after incision and drainage proving that systemic antibiotics do not significantly improve the percentage of patients with complete resolution of their abscesses ${ }^{[8]}$.

Another randomized control study on assess the efficacy of non-packing methods in abscess drainage. The results of the study showed the equal efficacy of packing and non-packing methods in terms of hemostasis and the prevention of reorganization of the abscess ${ }^{[9]}$.

The objective is to describe the practice of surgical doctors toward cutaneous abscess management in the surgical department of Khartoum and Bahri localities teaching hospitals.

\section{MATERIALS AND METHODS}

\section{$>$ Study Design and sample size:}

A descriptive Cross-sectional facility based study at the surgery emergency departments of the Khartoum and Bahri localities teaching hospitals, there were 5 teaching hospitals in Khartoum and Bahri localities that perform emergency operations for superficial abscesses (Ibrahim Malik, AL Academy, Bahri, Ali Abdalfatah, Haj Alsafy teaching hospitals). The doctors that working in the surgical emergency departments of Khartoum and Bahri localities teaching hospitals. Pre houseman doctors, house officers, medicals, registrars, specialists, and consultants were included in the study, others health professional that help in the operation like nurses and technicians were excluded. Only cutaneous superficial abscess were included in the study, perianal, breast, and organs abscesses were excluded.

Total coverage of all the study population in the study area had been performed and collected through several questions asked to doctors, the independent variables were socio-demographic characteristics of the respondents (Hospital name, age, gender, residency, working Status) Number of septic lists in the duty, Cardinal history points that usually inquire, Examination signs done routinely, laboratory investigations requested (Random blood sugar, urine general, $\mathrm{CBC}$ and culture and sensitivity to MRSA screen), Confirmation of diagnosis (aspiration, Ultra 
Sound), Types of anesthesia used (Local, General, regional), type of local anesthesia ( pure local anesthetic, mixed with bicarbonate), site of local anesthesia (tissues around the abscess, inside the abscess or the roof of the abscess), type of Incision (with skin crease or X shape), Procedure details (Probing, Irrigation Packing), type of packing ( iodine soaked, normal saline soaked or dry packing), post-operative Antibiotics, frequency of dressing(daily, day after day, or every two days).

\section{$>$ Data analysis:}

The data were entered and proceed using Microsoft office excel version 2013. Descriptive frequency table, cross tabulation and Chi-Square test were analyzed and interpreted using Statistical Package for Social Sciences (SPSS) version 23 software computer package.

\section{$>$ Ethical considerations}

Ethical approval obtained from ethics committee in the Graduate College, Medical and Health Studies Board University of Medical Sciences \& Technology, Khartoum state ministry of health research department, also from hospital's administration. Informed consent obtained from all medical doctors voluntary participating in the study.

\section{RESULTS}

The overall response rate of the study was $60 \%$, Ibrahim Malik Hospital had response rate of $60 \%$, Academy Hospital had 33\%, 76\% for Bahri Hospital, 72\% for Haj Alsafy Hospital, and Ali Abdel Fatah Hospital response rate was $81 \%$. Table 1

Mean age of the participants was found to be (26.66) years and the mean of surgical experience was (19.72) months. Out of a total of 127 participants, $48 \%$ were female and $52 \%$ were male, $44.1 \%$ of participants reside in Khartoum, $37.8 \%$ in Bahri and $18.1 \%$ in Omdurman. $27.6 \%$ of participants were found to be working in Ibrahim Malik Hospital, $11.0 \%$ in the Academy Hospital, 33.9\% in Bahri Hospital, $20.5 \%$ in Haj Alsafy Hospital, with the remaining $7.1 \%$ in Ali Abdelfatah Hospital. Among all participants $59.8 \%$ were found to be house officers, $7.9 \%$ were medical officers, $26.8 \%$ were registrars, $20.4 \%$ were specialists and only $3.1 \%$ were consultants. Only $24.4 \%$ of the participants were provided by the hospital with a protocol for the management of cutaneous abscesses. 10.2 $\%$ of participants were following the hospital protocol in their practice; while $76.4 \%$ follow their senior instructions, $11.8 \%$ apply British guidelines and $1.6 \%$ follows information from textbooks. $72.4 \%$ of participants operate one septic list per duty, while the remaining $27.6 \%$ operate two septic lists per duty. Table 2

Among all participants $85 \%$ were found to be asking patients about the presence of fever, $80.3 \%$ asked about a history of throbbing pain, $66.1 \%$ asked about history of trauma in the affected area, $61.4 \%$ asked about history of recurrence, and $46.5 \%$ inquire prior usage of any antibiotic. Among all participants $81.1 \%$ check the temperature, $66.1 \%$ check the pulse rate, $50.4 \%$ check the blood pressure, and $31.5 \%$ check the respiratory rate. Regarding the investigations needed $70.1 \%$ request random blood glucose, $64.6 \%$ request a urine general test, $91 \%$ order a CBC, and $33.1 \%$ of participants obtain blood cultures and, only $3.1 \%$ request MRSA screening. Table 3

About $68.5 \%$ were found to be aspirating the abscess to confirm the diagnosis, $14.2 \%$ of the participants used Ultrasound for conformation, while $28.3 \%$ of participants don't confirm the diagnosis. Among all participants $94.5 \%$ used local anesthesia for drainage of an abscess, $35.4 \%$ used regional anesthesia for drainage of abscesses, and $54.3 \%$ opted for general anesthesia. In the population using local anesthetics, $85 \%$ used pure local anesthesia for drainage of abscess, $1.6 \%$ used Local anesthetics mixed with Bicarbonate for drainage of abscess, and $14.2 \%$ used Local anesthetics mixed with Adrenaline, while $22.8 \%$ used Local anesthetics with Narcotics for drainage of an abscess. As for the route of administering their choice of local anesthetic, $94.5 \%$ of participants choose infiltration around the tissues of the abscess, $13.4 \%$ infiltrate the anesthesia inside the abscess cavity and $26 \%$ infiltrate the anesthesia at the abscess roof. Table 4

Regarding the indications for general anesthesia open ended question, $(5.5 \%)$ of the participants were found to be using general anesthesia for a head/neck abscess, $(27.6 \%)$ for a gluteal region abscess, (7.9\%) in a face abscess, (7.9\%) if drainage via local anesthesia fails, $(21.3 \%)$ in a genital abscess, (24.4\%) in deep abscess that require debridement, $(3.9 \%)$ in multiple abscesses, $(7.9 \%)$ if it's an upper limb abscess, (27.6) for a hand abscess, (3.9\%) in cases of a psychiatric patient, (15.0\%) for pediatric cases, and $(3.9 \%)$ in cases that are associated with/complicated by cellulitis. Among all participants, $96.1 \%$ of doctors were found to be following incision and drainage in their management, $22.0 \%$ adopting aspiration and antibiotics method of management, $72.4 \%$ choose the method of draining the abscess by incision with the skin crease, $37.8 \%$ used drainage of an abscess by an $\mathrm{X}$ shaped incision, $67.6 \%$ perform probing, $44.1 \%$ perform irrigation, $57.5 \%$ perform packing and $18.1 \%$ of the participants applying de-roofing in abscess drainage. Table 5

Among all participants $38.6 \%$ of participants use a normal saline soak packing after abscess drainage, $80.3 \%$ of participants use iodine soak packing and $15.7 \%$ of participants used dry packing. Among all participants $87.4 \%$ was prescribing antibiotics post-operatively on a routine basis. $9.4 \%$ prescribe Co-trimoxazole, $50.4 \%$ prescribe Amoxicillin, 6.3\% prescribe Doxycycline, 35.4\% prescribe Metronidazole, $3.1 \%$ prescribe Clindamycin, 59.1\% prescribe Augmentin, 26\% prescribe Cephalosporin, and $15 \%$ prescribe Macrolides. In the aforementioned group, $59.1 \%$ of participants used separated mode of antibiotics and $52 \%$ used combination mode. Table 6

Among all participants, $4.7 \%$ were found to be prescribing antibiotics for immune-deficient patients, $5.5 \%$ prescribe based on presence of signs and symptoms of infection, $3.5 \%$ administer antibiotics in patients with large 
ISSN No:-2456-2165

abscess, $1.6 \%$ prescribe for patients with a high total WBC's count and $3.9 \%$ due to presence of cellulitis. About $(51.2 \%)$ of the doctors were found to be applying daily dressing for abscess patients, (46.5\%) preferred day after day dressing and $(12.6 \%)$ was performing every two days dressing. Table 6

\begin{tabular}{|c|c|c|c|}
\hline & Participants Number & Total staff number & Response rate \\
\hline Ibrahim Malik Hospital & 35 & 65 & $60 \%$ \\
\hline Academy Hospital & 14 & 42 & $73 \%$ \\
\hline Bahri Hospital & 43 & 56 & $72 \%$ \\
\hline Haj Alsafy Hospital & 26 & 36 & $81 \%$ \\
\hline Ali Abdel Fatah Hospital & 9 & 11 & $60 \%$ \\
\hline
\end{tabular}

Table 1:- Response rate of the study participants $(n=127)$.

\begin{tabular}{|c|c|c|c|}
\hline & Mean & Median & Std. Deviation \\
\hline Age & 26.66 & 25 & 5.805 \\
\hline Surgical experience & 19.72 & 3 & 52.56 \\
\hline \multicolumn{2}{|c|}{ Variable } & Number & Percentage \\
\hline \multirow[t]{2}{*}{ Gender } & Female & 61 & 48 \\
\hline & Male & 66 & 52 \\
\hline \multirow[t]{5}{*}{ Residence } & Khartoum & 56 & 44.1 \\
\hline & Bahri & 48 & 37.8 \\
\hline & Omdurman & 23 & 18.1 \\
\hline & Ibrahim Malik Hospital & 35 & 27.6 \\
\hline & Academy Hospital & 14 & 11 \\
\hline \multirow[t]{5}{*}{ Hospital Name } & Bahri Hospital & 43 & 33.9 \\
\hline & Haj Alsafy Hospital & 26 & 20.5 \\
\hline & Ali Abdel Fatah Hospital & 9 & 7.1 \\
\hline & House officer & 76 & 59.8 \\
\hline & Medical officer & 10 & 7.9 \\
\hline \multirow[t]{3}{*}{ Current status } & Registrar & 34 & 26.8 \\
\hline & Specialist & 3 & 2.4 \\
\hline & Consultant & 4 & 3.1 \\
\hline \multirow[t]{2}{*}{ No Septic lists per duty } & One septic list per duty & 92 & 72.4 \\
\hline & Two septic lists per duty & 35 & 27.6 \\
\hline \multirow[t]{3}{*}{ Providing of Abscess protocol } & No & 96 & 75.6 \\
\hline & Yes & 31 & 24.4 \\
\hline & Senior instructions & 97 & 76.4 \\
\hline \multirow[t]{3}{*}{ Protocol of use } & Hospital protocol & 13 & 10.2 \\
\hline & British Guidelines & 15 & 11.8 \\
\hline & Text book information's & 2 & 1.6 \\
\hline
\end{tabular}

Table 2:- Socio-demographic variable, providing and using of the cutaneous abscess protocol $(\mathrm{n}=127)$. 
ISSN No:-2456-2165

\begin{tabular}{|c|c|c|c|}
\hline \multicolumn{2}{|l|}{ Variable } & \multirow{2}{*}{$\begin{array}{c}\text { Number } \\
19\end{array}$} & \multirow{2}{*}{$\begin{array}{c}\text { Percentage } \\
15\end{array}$} \\
\hline Fever & No & & \\
\hline & Yes & 108 & 85 \\
\hline Throbbing pain & No & 25 & 19.7 \\
\hline & Yes & 102 & 80.3 \\
\hline Trauma history & No & 43 & 33.9 \\
\hline & Yes & 84 & 66.1 \\
\hline Recurrence & No & 49 & 38.6 \\
\hline & Yes & 78 & 61.4 \\
\hline Prior Antibiotics & No & 68 & 53.5 \\
\hline & Yes & 59 & 46.5 \\
\hline Temperature & No & 23 & 18.1 \\
\hline & Yes & 104 & 81.9 \\
\hline Pulse rate & No & 43 & 33.9 \\
\hline & Yes & 84 & 66.1 \\
\hline Blood pressure & No & 63 & 49.6 \\
\hline & Yes & 64 & 50.4 \\
\hline Respiratory Rate & No & 87 & 68.5 \\
\hline & Yes & 40 & 31.5 \\
\hline Urine General & No & 45 & 35.4 \\
\hline & Yes & 82 & 64.6 \\
\hline Random Blood Glucose & No & 38 & 29.9 \\
\hline & Yes & 89 & 70.1 \\
\hline Complete Blood Count & No & 11 & 8.7 \\
\hline & Yes & 116 & 91.3 \\
\hline Culture and Sensitivity & No & 85 & 66.9 \\
\hline & Yes & 42 & 33.1 \\
\hline MARSA Screening & No & 123 & 96.9 \\
\hline & Yes & 4 & 3.1 \\
\hline
\end{tabular}

Table 3:- Demonstrate symptoms inquired in medical history and investigations examined by participants $(\mathrm{n}=127)$.

\begin{tabular}{|c|c|c|c|}
\hline \multicolumn{2}{|l|}{ Variable } & Number & Percentage \\
\hline \multirow[t]{2}{*}{ Aspiration } & No & 40 & 31.5 \\
\hline & Yes & 87 & 68.5 \\
\hline \multirow[t]{2}{*}{ Ultrasound } & No & 109 & 85.8 \\
\hline & Yes & 18 & 14.2 \\
\hline \multicolumn{2}{|c|}{ Doctors do not confirm Abscess diagnosis } & 36 & 28.3 \\
\hline & & & \\
\hline & local & 120 & 94.5 \\
\hline \multirow{2}{*}{ Type of anesthetics } & Regional & 45 & 35.4 \\
\hline & General & 69 & 54.3 \\
\hline \multirow[t]{2}{*}{ Doctors used pure local anesthetics } & No & 19 & 15 \\
\hline & Yes & 108 & 85 \\
\hline local anesthetics mixed with bicarbonate & No & 125 & 98.4 \\
\hline
\end{tabular}


ISSN No:-2456-2165

\begin{tabular}{|c|c|c|c|}
\hline & Yes & 2 & 1.6 \\
\hline local anesthetics mixed with Adrenaline & & & \\
\hline & No & 109 & 85.8 \\
\hline local anesthetics with Narcotics & Yes & 18 & 14.2 \\
\hline & & & 77.2 \\
\hline Local anesthetics Around the abscess & No & 98 & 22.8 \\
\hline & Yes & 29 & \\
\hline & No & 7 & 5.5 \\
\hline Local anesthetics inside the abscess cavity & Yes & 120 & 94.5 \\
\hline & & & \\
\hline & No & 110 & 86.6 \\
\hline Local anesthetics at the roof of the abscess & Yes & 17 & 13.4 \\
\hline & & & \\
\hline & No & 94 & 74 \\
\hline
\end{tabular}

Table 4:- Demonstrate the methods of diagnosis confirmation and type of anesthetic used by participants $(\mathrm{n}=127)$.

\begin{tabular}{|c|c|c|c|}
\hline \multicolumn{2}{|c|}{ Variable } & \multirow{2}{*}{$\begin{array}{c}\text { Number } \\
7\end{array}$} & \multirow{2}{*}{$\begin{array}{c}\text { Percent } \\
5.5\end{array}$} \\
\hline & Head and neck abscess & & \\
\hline & Gluteal region abscess & 35 & 27.6 \\
\hline & Face abscess & 10 & 7.9 \\
\hline & Failure of local anesthetics & 10 & 7.9 \\
\hline & Genitalia abscess & 27 & 21.3 \\
\hline \multirow[t]{7}{*}{ General anesthesia } & Deep abscess that needs debridement & 31 & 24.4 \\
\hline & Multiple abscess & 5 & 3.9 \\
\hline & Upper limb abscess & 10 & 7.9 \\
\hline & Hand abscess & 35 & 27.6 \\
\hline & Patients with Psychiatry illness & 5 & 3.9 \\
\hline & Pediatrics & 19 & 15 \\
\hline & Cellulitis & 5 & 3.9 \\
\hline \multirow[t]{2}{*}{ Incision and drainage } & No & 5 & 3.9 \\
\hline & Yes & 122 & 96.1 \\
\hline \multirow[t]{2}{*}{ Aspiration and antibiotics } & No & 99 & 78 \\
\hline & Yes & 28 & 22 \\
\hline \multirow[t]{2}{*}{ Incision with skin crease } & No & 35 & 27.6 \\
\hline & Yes & 92 & 72.4 \\
\hline \multirow[t]{2}{*}{ X Shape incision } & No & 79 & 62.2 \\
\hline & Yes & 48 & 37.8 \\
\hline \multirow[t]{2}{*}{ Probing } & No & 41 & 32.3 \\
\hline & Yes & 86 & 67.7 \\
\hline \multirow[t]{2}{*}{ Irrigation } & No & 71 & 55.9 \\
\hline & Yes & 56 & 44.1 \\
\hline \multirow{2}{*}{ Packing } & No & 54 & 425 \\
\hline & Yes & 73 & 57.5 \\
\hline \multirow[t]{2}{*}{ Deroofing } & No & 104 & 81.9 \\
\hline & Yes & 23 & 18.1 \\
\hline
\end{tabular}

Table 5:- Indication of General anesthesia and operative techniques of abscess drainage ( $\mathrm{n}=127)$. 
ISSN No:-2456-2165

\begin{tabular}{|c|c|c|c|}
\hline \multicolumn{2}{|c|}{ Variable } & \multirow{2}{*}{$\begin{array}{c}\text { Number } \\
107 \\
\end{array}$} & \multirow{2}{*}{$\begin{array}{c}\text { Percentage } \\
84.3\end{array}$} \\
\hline Dry packing & No & & \\
\hline & Yes & 20 & 15.7 \\
\hline \multirow{2}{*}{ Normal saline soaked gauze } & No & 78 & 61.4 \\
\hline & Yes & 49 & 38.6 \\
\hline \multirow[t]{2}{*}{ Iodine Soaked gauze } & No & 25 & 19.7 \\
\hline & Yes & 102 & 80.3 \\
\hline \multirow[t]{5}{*}{ Post-operative antibiotics for every abscess patient } & No & 16 & 12.6 \\
\hline & Yes & 111 & 87.4 \\
\hline & Co-trimixazole & 12 & 9.4 \\
\hline & Amoxicillin & 64 & 50.4 \\
\hline & Doxycycline & 8 & 6.3 \\
\hline \multirow[t]{5}{*}{ Antibiotics of choice } & Metronidazole & 45 & 35.4 \\
\hline & Clindamycin & 4 & 3.1 \\
\hline & Augmentin & 75 & 59.1 \\
\hline & Cephalosporin & 33 & 26 \\
\hline & Macrolides & 19 & 15 \\
\hline \multirow[t]{5}{*}{ Mode of use of Antibiotics } & Separated & 75 & 59.1 \\
\hline & In combination & 52 & 40.9 \\
\hline & & & \\
\hline & Immunodeficient patients & 6 & 4.7 \\
\hline & Presence of signs and symptoms of infection & 7 & 5.5 \\
\hline \multirow{3}{*}{ Indication of antibiotics } & Large abscess & 4 & 3.1 \\
\hline & High total WBCS count & 2 & 1.6 \\
\hline & Presence of cellulitis & 5 & 3.9 \\
\hline & & & \\
\hline \multirow[t]{2}{*}{ Daily dressing } & No & 62 & 48.8 \\
\hline & Yes & 65 & 51.2 \\
\hline \multirow[t]{2}{*}{ Day after day } & No & 68 & 53.5 \\
\hline & Yes & 59 & 46.5 \\
\hline \multirow[t]{2}{*}{ Every two Days } & No & 111 & 87.4 \\
\hline & Yes & 16 & 12.6 \\
\hline
\end{tabular}

Table 6:- The packing of mode, antibiotic prescription and indication manners and dressing modes of the participants ( $\mathrm{n}=127)$.

\section{DISCUSSION}

The study showed that with regards to physicians approach to patients with cutaneous abscesses, major points related to the local and systemic manifestations of abscesses were thoroughly covered throughout the state, with the majority of physicians enquiring about fever, throbbing pain, history of trauma along with the history of recurrence of the condition. The use of antibiotics prior to hospital presentation was a point of some controversy and was not as thoroughly covered as the aforementioned points, with roughly half $(46.5 \%)$ choosing to enquire about prior antibiotic use, whereas others chose not to. While these points can be viewed as a strong positive with regards to the primary approach of physicians towards cutaneous abscesses, prior antibiotic use for the same abscess should be routinely enquired, as their use prior to drainage may lead to a different approach towards the condition due to the formation of Antibioma ${ }^{[7]}$.

The majority of physicians participating in the study thoroughly assessed patient temperature (82\%), however the pulse rate along with the respiratory rate were not as enthusiastically approached, with $(66 \%)$ and $(68 \%)$ of physicians asking about the pulse and respiratory rate respectively. Patients' blood pressure was also a point of poor approach with almost half of the physicians $(50.6 \%)$ choosing not to assess the patients' blood pressure. This sheds light on a major issue with regards to patient care. The following physical findings have all been previously mentioned with regards to Systemic Inflammatory Response Syndrome (SIRS), a point to be carefully considered for several reasons. First and foremost SIRS is a predecessor to sepsis and septic shock. It is the reaction of the body towards systemic inflammation and an important 
early marker for physicians, allowing simple and common conditions to be treated before reaching a devastating end result. The second point has been previously mentioned in the guidelines, as SIRS is an indication to the blind use of antibiotics without culture results. These two factors represent a point of consideration with regards to physician practice and patient benefit ${ }^{[1]}$.

Regarding routine investigations requested by practicing physicians, a wider spectrum of practice is observed with $(91 \%)$ of physicians requesting a complete blood count from their patients, $(70 \%)$ of physicians routinely requesting patient random blood glucose measurement, and $64 \%$ ordering urine analysis. The vast majority of physicians chose not to order culture and sensitivity, with only (33\%) of physicians stating culture and sensitivity as a routine investigation for patients with cutaneous abscesses. MRSA screening via nasal swab and skin swab, was a point of poor response with the majority (97\%) choosing not to order this investigation as a part of the routine management. These findings can be assessed in several ways, partly owing to physician practice, keeping in mind the limited facilities accessible at teaching hospitals around Khartoum. The socio economic status of patients also plays a role in deciding what investigations are ordered, as most patients cannot afford investigations such as culture and sensitivity. Investigations such as culture and sensitivity and MRSA screening are neither feasible nor applicable especially in our study area which including the public teaching hospitals which offering general medical service to the population that has high prevalence of poverty. Financial considerations made in the patient's best interest are also a part of the physician's responsibility towards his/her patients. Doctor's majority practice of asking for routine investigations as preparation for cutaneous abscess incision and drainage process, don't have any clinical weight or importance and represent financial load either on the patients directly or in the health insurance system for patient that has health insurance. This points of investigation apart from culture and sensitivity not covered in the guidelines but have been discussed in Singhal H et al ${ }^{[8]}$.

Regarding the confirmation of diagnosis majority of the participants $(68.5 \%)$ aspirating the abscess to confirm the diagnosis, minority $(14.2 \%)$ of the participants used Ultrasound for conformation, while the rest of them (28.3\%) don't confirm the diagnosis, confirmation of diagnosis is not discussed in the guidelines but aspiration is recommended in (Surgical Care at the District Hospital) textbook when there is doubt in the abscess diagnosis, bedside ultrasound usage when the history and physical examination is not clear enough to take decision, is recommended by Grimm ${ }^{[3]}$.

Anesthesia is the major part of the cutaneous abscess incision and drainage, the vast majority (94.5\%) of the participant used local anesthesia for drainage of an abscess, $(35.4 \%)$ used regional anesthesia, and the $(54.3 \%)$ opted for general anesthesia. (1.6\%) used Local anesthetics mixed with Bicarbonate for drainage of abscess; bicarbonate can improve the function of local anesthetics by neutralizing the acidic media. Only (26\%) infiltrate the anesthesia at the abscess roof so the remaining doctors will cause pain for their patients at the time of skin incision. (94.5\%) of the doctors injecting local anesthetics into tissue around the cavity which is beneficial for pain sedation of patients ${ }^{[4]}$.

Indication of general anesthesia including large abscess that needs debridement, local and field block is recommended for the small abscess ${ }^{[4]}$. but there is many indications rather than large abscess for general anesthesia in our study physicians points of view such as, Head and neck abscess, Gluteal region abscess, Face abscess, Failure of local anesthetics, Genitalia abscess, Multiple abscesses, Upper limb abscess, Hand abscess, Patients with Psychiatry illness, Pediatrics patients and association with Cellulitis these aspects not covered in the guidelines and no article or scientific work organizes when to choose general anesthetics for cutaneous abscess patients.

The vast majority of $(96.1 \%)$ doctors following incision and drainage method in their management which is recommended by all the guidelines [1, 6], about $(22.0 \%)$ adopting aspiration and antibiotics method of management which no longer recommended. Majority of doctors (72.4\%) applying incision with the skin crease which is recommended for prevention of unsightly scars, (37.8\%) used drainage of an abscess by an X-shaped incision, large percentage of participants $(32.3 \%)$ do not perform probing which is crucial for breaking of pus flocculation and therefore complete drainage and prevention of recurrence, and its recommended by the guidelines ${ }^{[4,5]},(55.9 \%)$ do not perform irrigation which results in incomplete wash out of the cavity contents in treated patients, irrigation is also recommended by Singhal et al ${ }^{[4]}$, minority of participants (18.1\%) applying de-roofing in abscess drainage and none of the scientific article and guidelines discussed the process of the cutaneous abscess deroofing. Packing of cutaneous abscess represents a point of controversy 4 because it is very painful in dressing some doctors avoiding it, about half $(57.5 \%)$ of the study participants applying packing. The results Leinwand Michael study showed the equal efficacy of packing and non-packing methods in terms of hemostasis and the prevention of reorganization of the abscess, and non-packing is superior in the aspect related to pain reduction ${ }^{[9]}$. In general term, operative details of the cutaneous abscess drainage are not well covered in the different guidelines, texts, and articles, which create a gap between doctor's practice and evidence that organize this practice.

Regarding postoperative antibiotics prescription for cutaneous abscess patients, the vast majority (87.4\%) of the study participants prescribing postoperative antibiotics routinely for patients after incision and drainage, only (12.6\%) prescribing antibiotics when there is an indication. A Singer and his colleague study showed antibiotics insignificant role in cutaneous abscess cure rates ${ }^{[8]}$, indication of antibiotics prescription is the only factor that discussed in all cited guidelines because of its importance, trends of the health institutes around the world running 
toward reduction of antibiotics prescription through guidelines because of the antibiotics resistance that threatening the world specially Africa, and one of the most important organisms that reflected antibiotics resistance is Staphylococcus aureus which is the major causative agents of the cutaneous abscess. This behavior of routine postoperative antibiotics prescription for abscess patients without indication will enlarge the danger of resistant Staphylococcus aureus, particularly methicillin-resistant Staphylococcus aureus ${ }^{[11]}$. All indications of postoperative antibiotics prescription mentioned by doctors in their $\underset{[\mathbf{1}, \mathbf{6}]}{\text { practice }}$ are discussed and supported by the cited guidelines

Half (51.2\%) of doctors applying daily dressing for abscess patients and this practice is recommended by Grimm ${ }^{[3]}$ and the rest half applying day after day or every two days dressing no studies compared between three patterns of dressing.

Overall Study response rate of the study was good, but it is affected by the low response rate of the academy teaching hospital. Specialist and consultants low response rate was also one of the limitations, some selection bias happened because of the $40 \%$ that did not participate in the study, doctors report their practice through filing the surveys which created a margin of error, no others limitations were found to be in the study.

\section{CONCLUSIONS}

Study participants showed different patterns of practice in cutaneous abscess management, part of this was supported by the guidelines and many were not, senior instructions determined the majority practice of doctors toward cutaneous abscess management, routine prescription of postoperative antibiotics was one the important findings of the study. Important aspects of cutaneous abscess management were not covered in the guidelines including anaesthesia, operative details, and dressing patterns.

\section{REFERENCES}

[1]. Stevens DL, Bisno AL, Chambers HF, Everett ED, Dellinger P, Goldstein EJC et al. Practice Guidelines for the Diagnosis and Management of Skin and Soft Tissue Infections: Update by the Infectious Diseases Society of America.2014. doi:10.1093/cid/ciu296.

[2]. Dobson M, Fenton P, Fisher R, Lett R, Mathai M, Wasunna A et al. Surgical Care at the District Hospital. London: WHO [serial online]. 2003 [Cited 2017 July]; Available from: URL:http://www.who.int/surgery/publications/en/SC DH.pdf.

[3]. Grimm LJ. Abscess Evaluation using Bedside Ultrasonography: Overview, Indications, and Contraindications. [Serial online]. 2015 [Cited 2017 July]; Available from: URL:http://emedicine.medscape.com/article/1379916overview.
[4]. Singhal H, RAB KK. Skin and Soft Tissue Infections - Incision, Drainage, and Debridement Periprocedural Care: Patient Education and Consent, Preprocedural Planning, Equipment. [Serial online]. 2017 [Cited 2017 July]; Available from: http://emedicine.medscape.com/article/1830144periprocedure.

[5]. Stevens DL, Bisno AL, Chambers HF, Everett ED, Dellinger P, Goldstein EJC et al. Practice Guidelines for the Diagnosis and Management of Skin and SoftTissue Infections. Clin. Infect Dis. 2016. doi:10.1086/497143.

[6]. John Hopkins Medicines. Antibiotics Guidelines 2015-2016. [Serial online]. 2016 [Cited 2017 July]; Available from: https://www.hopkinsmedicine.org/amp/guidelines/anti biotic guidelines.pdf.

[7]. Williams NS, Christopher J.K. Bulstrode PRO. Short Practice of Surgery, Bailey and Love. 2013

[8]. Singer AJ, Thode HC. Systemic antibiotics after incision and drainage of simple abscesses: a metaanalysis. Emerg Med J. 2014. 31(7):576-578. Doi: 10.1136/emermed-2013-202571.

[9]. Leinwand M, Downing M, Slater D, Beck M, Burton $\mathrm{K}$, Moyer D. Incision and drainage of subcutaneous abscesses without the use of packing. J Pediatr Surg. 2013 48(9):1962-1965. doi:10.1016/j.jpedsurg.2013.01.027.

[10]. Taira BR, Singer AJ, Thode HC, Lee CC. National epidemiology of cutaneous abscesses: 1996 to 2005. Am J Emerg Med. 2009. 27(3):289-292. doi:10.1016/j.ajem.2008.02.027.

[11]. Schaumburg F, Alabi AS, Peters G, Becker K. New epidemiology of Staphylococcus aureus infection in Africa. Eur Soc Clin Infect Dis. 2014. 20:589-596. doi:10.1111/1469-0691.12690. 